\title{
DECORING BEHAVIOUR OF CHOSEN MOULDING MATERIALS WITH ALKALI SILICATE BASED INORGANIC BINDERS
}

\begin{abstract}
This paper contains basic information about new processes for cores for cylinder heads production with alkali silicate based inorganic binders. Inorganic binders are coming back to the foreground due to their ecologically friendly nature and new technologies for cores production and new binder systems were developed. Basically these binder systems are modified alkali silicates and therefore they carry some well-known unfavourable properties with their usage. To compensate these disadvantages, the binder systems are working with additives which are most often in powder form and are added in the moulding material. This paper deals with decoring behaviour of different moulding sands as well as the influence of chosen additives on knock-out properties in laboratory terms. For this purpose, specific methods of specimen production are described. Developed methods are then used to compare decoring behaviour of chosen sands and binder systems.
\end{abstract}

Keywords: Inorganic binder, alkali silicate, moulding material, knock-out properties

\section{Introduction}

Foundries are constantly under pressure of stringent environmental requirements and safety regulations. Nowadays, sand cores are most often produced from resin-bonded silica sands, which release emissions and related odour not only during casting but also during core production process. Therefore there is a tendency to replace them with almost harmless binding materials [1]. This resulted into demand for alternative ecologically friendly binder system and inorganic binders came into the centre of attention [2]. Managing the demanding technological requirements of organic binder systems which result from the increasing demands on castings quality represents grand challenges for inorganic binder systems developers [3]. In November 2002 in Wuppertal, at VDG conference with subject of guiding the inorganic binder systems to the foreground was discussed the use of inorganic binders in foundries [2]. Inorganic binders based on modified silicate or water glass solutions as new binder systems, which are cured by heat were presented at GIFA 2003 by several binder manufacturers. The foundation of these hot-curing processes was the fact, that moulding materials with "classic" water glass binder can attain significantly higher strengths by drying when using heated tools [4-6]. However, developers of inorganic binder systems significantly improved binder properties, still there is a connection to technological problems compared to resin-bonded sands such as low knockout properties, low ability to reclaim [7] and limited storage of cores [3]. This paper is focused on comparison of decoring behaviour of moulding material with different types of sands and additives.

\subsection{Hot-curing process}

Principle of hot-curing process with inorganic binder systems consists of blowing moulding material into a heated core box on commercial core blowing machines. Core box is usually heated between $100-200^{\circ} \mathrm{C}$ depending mainly on core geometry, but also on binder system used [5,8-10]. When the moulding mixture is in the core box, due to a heat a shell along the outer contour of the core is being formed. Whole process is ideally accelerated by purge of the hot air, which improves heating of moulding material and at the same time efficiently drains off the water expulsed during curing. Curing process has mainly physical basis - drying of solvent water, but also chemical reaction can be triggered depending on binder system used [5]. In laboratory terms there can be used several types of equipment for specimen production from different manufacturers $[11,12]$.

\footnotetext{
* TECHNICAL UNIVERSITY OF KOŠICE, FACULTY OF METALLURGY, INSTITUTE OF METALLURGY, LETNÁ 9, 042 00 KOŠICE, SLOVAKIA

** NEMAK SLOVAKIA S.R.O., ŽIAR NAD HRONOM

\# Corresponding author: iveta.vaskova@tuke.sk
} 


\section{Methods for knock-out properties evaluation}

As mentioned before using alkali silicate binders is connected with some unfavourable technological problems, one of the main focuses is on the knock-out properties. Knock-out properties are defined as ability of sand mould or sand core to disintegrate after casting (thermal load) and cooling down to knocking-out (decoring) temperature [13]. Over times several methods for knock-out properties evaluation for moulding materials with alkali silicate based binders were developed. Most used methods are $[14,15]$ :

- Evaluation method of the knocking-out properties recommended by the Polish standard PN-85/H-11005,

- Evaluation of the knocking-out properties based on the measurement of the residual strength.

Since the technological method by the Polish standard $\mathrm{PN}-85 / \mathrm{H}-11005$ requires mould to be from the same moulding material as test samples it would be very complicated to use it for the hot-curing process.

\section{Materials and methods}

Aim of this investigation was to develop simple method for knock-out properties estimation and to use it for measurement of different foundry sands bonded with new inorganic binder systems cured by heat. List of tested foundry sands and inorganic binder systems is presented in Table 1 below.

TABLE 1

List of tested foundry sands and binder systems

\begin{tabular}{|c|c|c|c|c|c|c|}
\hline \hline \multirow{2}{*}{ Marking } & \multicolumn{2}{|c|}{ Sand } & \multicolumn{2}{c|}{ Binder } & \multicolumn{2}{c|}{ Powder additive } \\
\cline { 2 - 7 } & Type & AFS & Type & $\begin{array}{c}\text { Amount } \\
{[\%]}\end{array}$ & Type & $\begin{array}{c}\text { Amount } \\
{[\%]}\end{array}$ \\
\hline A & SH32 & 40 & A & 2 & 1 & 0,9 \\
\hline B & SH35 & 70 & A & 2 & 1 & 0,9 \\
\hline C & $\begin{array}{c}\text { SH32:SH35 } \\
(70: 30)\end{array}$ & 50 & A & 2 & 1 & 0,9 \\
\hline D & SH32 & 40 & B & 2 & 2 & 1,8 \\
\hline E & SH32 & 40 & B & 2 & 3 & 0,8 \\
\hline F & ST52 & 50 & A & 2 & 1 & 0,9 \\
\hline G & ST54 & 65 & A & 2 & 1 & 0,9 \\
\hline H & MinSand & 65 & A & 2 & 1 & 0,9 \\
\hline I & Cerabeads & 65 & A & 2 & 1 & 0,9 \\
\hline J & Chromite & 45 & A & 2 & 1 & 0,9 \\
\hline
\end{tabular}

Silica sand from locality Šajdíkove Humence of two granulometries and their combination was used [16]. Alternative sands were also tested: Silica sand from locality Střeleč with angular grain, MinSand (bauxite basis, perfect round grain) and Cerabeads (mullite basis, perfect round grain with large surface).

Binder A with powder additive 1 (organic compound containing) was tested for all sands in order to determine decoring behaviour of different sand types and binder $\mathrm{B}$ with additives 2 and 3 (both fully inorganic) were tested for comparison of different binder system influence on decoring behaviour.

\subsection{Cylinder samples production parameters and residual strength measurement}

First part of examination was divided into two steps, first establishing parameters for cylinder samples production using the Morek Multiserw core blower for HB/WB systems (not equipped by hot air gassing unit), second step was to measure residual strength for foundry sand $\mathrm{SH} 32$ with $2 \%$ of inorganic binder $A$ and $0,9 \%$ powder additive 1 , which is organic containing and therefore should ensure the best decoring behaviour. This moulding material was established as a reference point for all other measurements.

A temperature of core box was set up as constant to $180^{\circ} \mathrm{C}$, blowing time was established for $0.5 \mathrm{~s}$. Fig. 1 shows how curing time influences the shell formation.

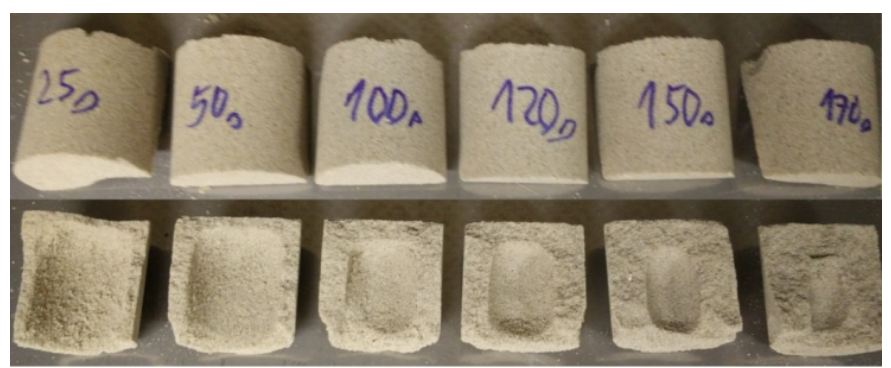

Fig. 1. Shell formation in dependence of curing time (from left 25, 50, $100,120,150,170$ seconds)

After series of blows, $100 \mathrm{~s}$ curing time was evaluated as optimal from the manipulation point of view, rest of uncured moulding material inside was "post-cured" due to the accumulated heat within several minutes. The same principle works for geometrically diverse cores with thin and thick walls, where shell in thick parts needs only to be formed enough to not collapse or bend the whole core.

Second step was measurement of residual strength for the same moulding material. Cylinder samples were exposed to thermal load in a furnace heated up on the demanded temperature. First, the time of exposition was measured by inserting a thermocouple inside a cylinder sample. For example there is given a graph (Fig. 2) that shows cylinder sample was heated to $800^{\circ} \mathrm{C}$ after 53 minutes.

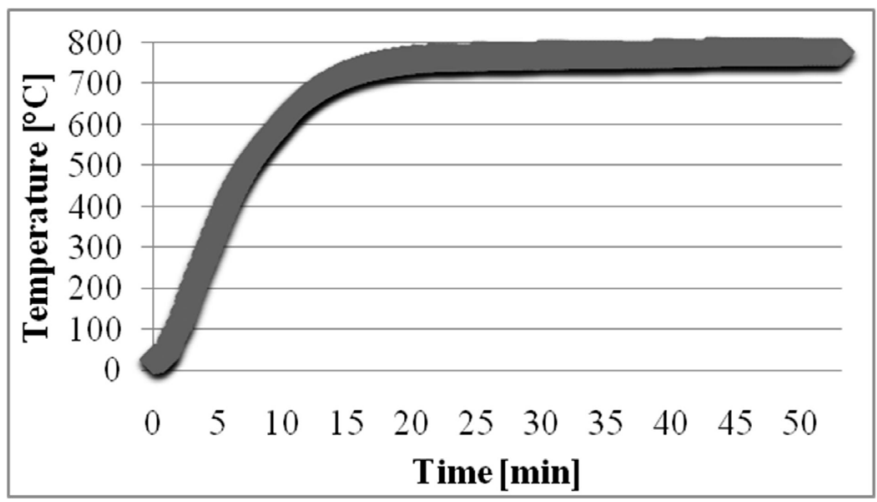

Fig. 2. Graph of heating cylinder sample to $800^{\circ} \mathrm{C}$ 
The same way were determined times in furnace for $200^{\circ} \mathrm{C}$, $400^{\circ} \mathrm{C}$ and $600^{\circ} \mathrm{C}$ to $26 \mathrm{~min}, 30 \mathrm{~min}$ and $27 \mathrm{~min}$. After thermal load and cooling to ambient temperature the residual strength was measured.

\subsection{Measurement of shear strength after thermal load}

First developed method is based on measuring shear strength on cylinder samples after being exposed to thermal load (similar to the residual strength method). The reason why shear strength measuring was chosen is always the same fracture surface of samples as well as higher possibilities of breaking samples with higher strength (non-silica sands). Thermal load was set up to $400^{\circ} \mathrm{C}$ for 15 minutes and 30 minutes (as measured by thermocouple in the previous section). After cooling down to the ambient temperature shear strength was measured.

Second developed method is not working with cylinder samples, but with test bars. Test bars were produced using the Benet Laboratory core test bars blower (with hot air purging) with blowing parameters presented in Table 2.

TABLE 2

Blowing parameters for test bars production

\begin{tabular}{|c|c|c|c|c|c|c|}
\hline $\begin{array}{c}\text { Core box } \\
\text { tempera- } \\
\text { ture }\end{array}$ & $\begin{array}{c}\text { Hot air } \\
\text { tempera- } \\
\text { ture }\end{array}$ & $\begin{array}{c}\text { Blow } \\
\text { pressure }\end{array}$ & $\begin{array}{c}\text { Gassing } \\
\text { pressure }\end{array}$ & $\begin{array}{c}\text { Exhaust } \\
\text { pressure }\end{array}$ & $\begin{array}{c}\text { Delay } \\
\text { time for } \\
\text { hot air }\end{array}$ & $\begin{array}{c}\text { Hot air } \\
\text { purging }\end{array}$ \\
\hline $180^{\circ} \mathrm{C}$ & $100^{\circ} \mathrm{C}$ & $3 \mathrm{bar}$ & $2 \mathrm{bar}$ & $2 \mathrm{bar}$ & $35 \mathrm{~s}$ & $20 \mathrm{~s}$ \\
\hline
\end{tabular}

Test bars were then also exposed to the thermal load of $400^{\circ} \mathrm{C}$ for 10 minutes. Time of the exposition was determined by thermocouple inserted inside a test bar (same method as in section 3.1). After cooling down to the ambient temperature test bars were shortened ca. by half (to $7.5-8 \mathrm{~cm}$ ) and putted inside $+\mathrm{GF}+$ abrasion resistance measuring device and abrasion as a statement of decoring behaviour was measured.

\section{Results}

Following graph (Fig. 3) represents measurement for mixture $\mathrm{A}$ according to the residual strength method. It can be seen that residual strength decreases with increased thermal load and thus it can be stated that mixture $\mathrm{A}$ has a good decoring behaviour around $600-800^{\circ} \mathrm{C}$. It means that parts of cores which are not heated to these temperatures - like core stampings, will have higher residual strength. In fact, this could be considered as an advantage when pouring cylinder heads - core stampings are not breaking when extracting a casting from mould.

Next diagram (Fig. 4) show results of developed method described in section 3.2 - measurement of shear strength after thermal load for different sand types and binder systems. It can be seen that silica sands are characterised by lower strength after thermal load than non-silica sands. In [16] authors stated that

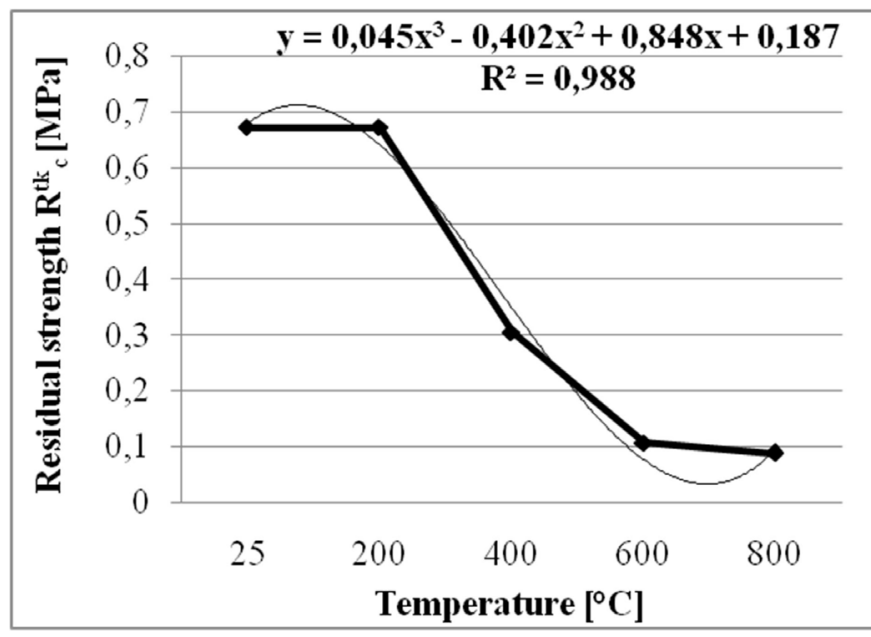

Fig. 3. Residual strength measurement of mixture A

certain combination of two granulometries of sand is positively influencing bending strength, but from the decoring behaviour point of view it seems to be influenced negatively. Also tested fine silica sands exhibit higher shear strength than coarse silica sands. Non-silica sands are having highest shear strength after thermal load and the samples did not break during testing. This method showed that the best decoring behaviour had a mixture E with binder $\mathrm{B}$ and powder additive 3 .

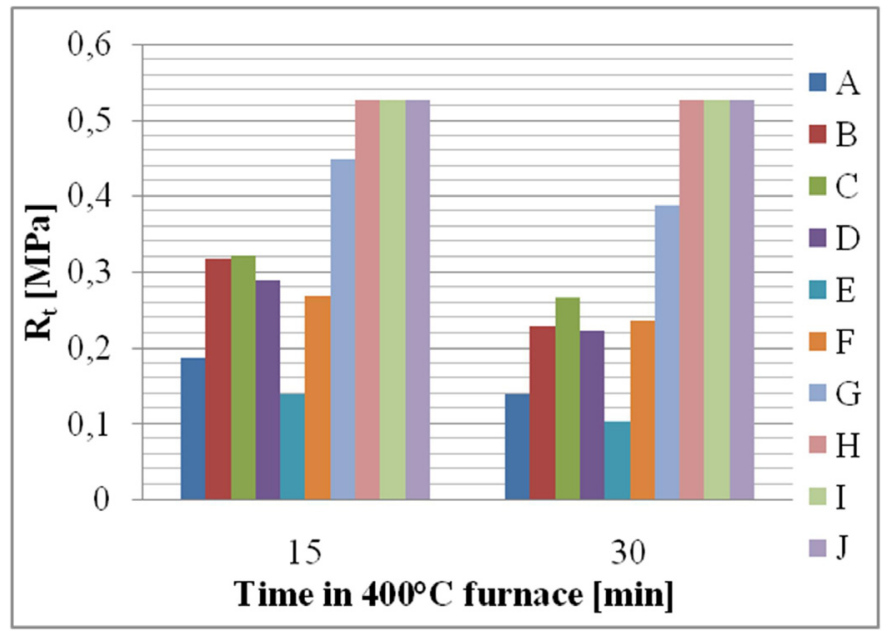

Fig. 4. Results of shear strength after thermal load measurement

Second developed method for decoring behaviour evaluation was abrasion measurement after heating to $400^{\circ} \mathrm{C}$ and the results are presented in Fig. 5:

Based on obtained results it can be stated that outcomes from a second method correspond with outcomes of first method and in addition there could be seen some differences between non-silica sands. Mixture E, which had the best decoring behaviour using the first method, had almost 100\% abrasion. From chosen non-silica sands, Cerabeads seems to have best knockout properties and MinSand the worst, which is connected with reaching very high strength with same binder level when using this sand compared to another sands (both silica and non-silica). 


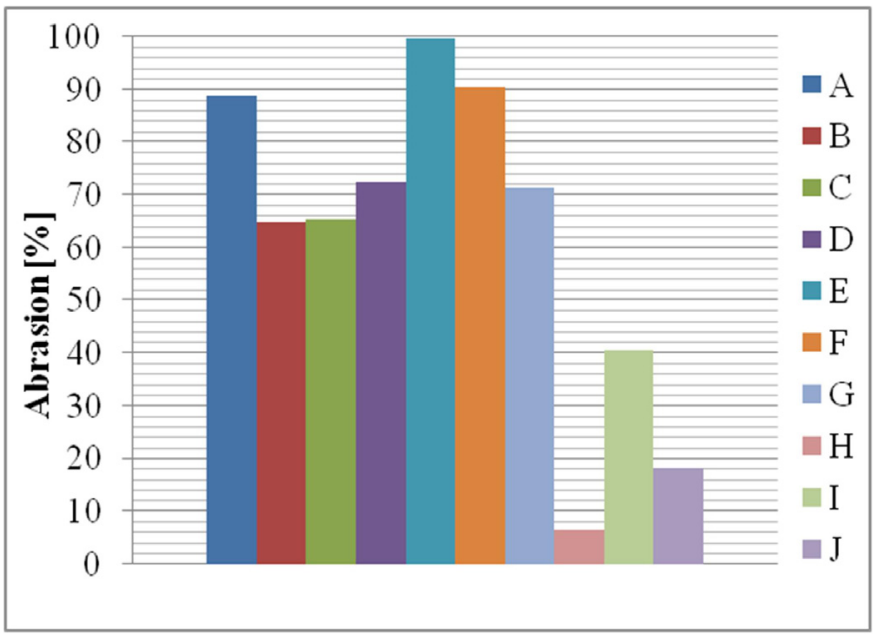

Fig. 5 Results of abrasion resistance after thermal load

\section{Conclusions}

Alkali silicate based binders still remain the most environmentally friendly binders available for use in foundry industry. GIFA, in 2003, is considered as breaking point, when the several leading manufacturers of binders for foundry industry presented their progress in the development of new inorganic binder systems. Nowadays, these two-component systems cured by heat were successfully implemented in the high-volume production of aluminium castings for automotive industry(cylinder heads and engine blocks). Although a great progress in the inorganic binder systems were made, there are still some well-known technological problems remained. One of the most dreaded is knock-out property. Measurement of decoring behaviour is very important for praxis and the purpose of this paper was to develop simple method for its evaluation. Based on the results in experimental part of this paper, following conclusions can be made:

- When using Morek Multiserw Universal Core Blower without hot air gassing unit for cylinder samples production, optimal parameters are $180^{\circ} \mathrm{C}$ core box temperature with $0,5 \mathrm{~s}$ blow time and $100 \mathrm{~s}$ curing time.

- Based on residual strength method, silica sand SH32 with $2 \%$ binder $\mathrm{A}$ and $0,9 \%$ powder additive 1 has a best knockout property around $600-800^{\circ} \mathrm{C}$.
- Both developed method exhibit similar outcomes in decoring behaviour of chosen moulding materials, but they can be assumed as reliable only after double checking either in real castings production or in production of test casting designed for it.

- $\quad$ From all tested materials mixture E with SH32, binder B and additive 3 exhibited the best decoring behaviour using both methods and the worst decoring behaviour showed mixture $\mathrm{H}$ with MinSand, binder $\mathrm{A}$ and additive 1. For mixture $\mathrm{H}$ it needs to be said that the result is connected with high compatibility of MinSand with binders (not only inorganic) resulting in higher strengths.

\section{REFERENCES}

[1] J. Wang, Z. Fan, H. Wang, X. Dong, N. Huang, China Foundry 4 (1), 026-030 (2007).

[2] K. Loechte, R. Boehm, Casting plant + Technology International 3, 6-11 (2005).

[3] J. Müller,et al, Slévárenství 7-8, 235-240 (2015).

[4] M. Franken, Giesserei 6, 182-184(2003).

[5] H. Polzin, Inorganic binders for mould and core production in the foundry, 2014 Schiele\&Schön GmbH, Berlin.

[6] R. Škuta, Dehydration processes of alkaline silicates hardening, 2014 TU v Košiciach, Slovakia.

[7] S.M. Dobosz, P. Jelínek, K. Major-Gabryś, China Foundry 8 (4), 438-446 (2011).

[8] J. Mueller, G. Weicker, J. Koerschgen, Giesserei-Praxis 05/2007, 192-194 (2007).

[9] C. Birnbaum, Entwicklung enbei anorganischen Formstoffsystemen im Zeitraum 1998-2008, 2009 TU BA Freiberg.

[10] L. Zaretskiy, International Journal of Metalcasting 10 (1), 88-99 (2016).

[11] http://www.benetlab.com/

[12] http://multiserw-morek.pl/

[13] J.L. Lewandowski, Tworzywa na formy odlewnicze, 1997 Kraków.

[14] I. Izdebska-Szanda, M. Angrecki, S. Matuszewski, Archives of Foundry Engineering 2 (Spec. Iss. 2), 117-120 (2012).

[15] K. Major-Gabrys, S.M. Dobosz, P. Jelínek, J. Jakubski, J. Beňo, Arch. Metall. Mater.59 (2), 739-742 (2014).

[16] M. Conev, I. Vasková, M. Hrubovčáková, P. Hajdúch, Manufacturing Technology 16 (2), 327-334 (2016). 